\section{(2) OPEN ACCESS}

\title{
Incidence of venous and arterial thromboembolic events reported in the tofacitinib rheumatoid arthritis, psoriasis and psoriatic arthritis development programmes and from real-world data
}

\author{
Philip Mease (1), ${ }^{1}$ Christina Charles-Schoeman, ${ }^{2}$ Stanley Cohen, ${ }_{1}^{3}$ Lara Fallon, ${ }^{4}$ \\ John Woolcott, ${ }^{5}$ Huifeng Yun, ${ }^{6}$ Joel Kremer, ${ }^{7}$ Jeffrey Greenberg, ${ }^{8}$ Wendi Malley, ${ }^{8}$ \\ Alina Onofrei, ${ }^{8}$ Keith S Kanik, ${ }_{1}^{9}$ Daniela Graham ${ }_{1}^{9}$ Cunshan Wang ${ }_{1}^{10}$ Carol Connell, ${ }^{11}$ \\ Hernan Valdez, ${ }^{12}$ Manfred Hauben, ${ }^{13,14}$ Eric Hung, ${ }^{13}$ Ann Madsen, ${ }^{15}$ Thomas V Jones, ${ }^{16}$ \\ Jeffrey R Curtis (1) ${ }^{17}$
}

\begin{abstract}
Handling editor Josef $S$ Smolen

- Additional material is published online only. To view please visit the journal online (http://dx.doi.org/10.1136/ annrheumdis-2019-216761)
\end{abstract}

For numbered affiliations see end of article.

Correspondence to Philip Mease, Seattle Rheumatology Associates, 601 Broadway, Suite 600, Seattle, WA 98102, USA : pmease@philipmease.com

Received 3 December 2019 Revised 16 June 2020 Accepted 17 June 2020 Published Online First 5 August 2020

\section{SLinked}

- http://dx.doi.org/10.1136/ annrheumdis-2020-218915

Check for updates

(C) Author(s) (or their employer(s)) 2020. Re-use permitted under CC BY-NC. No commercial re-use. See rights and permissions. Published by BMJ.

To cite: Mease $P_{1}$ Charles-

Schoeman C, Cohen S,

et al. Ann Rheum Dis

2020:79:1400-1413.

\section{ABSTRACT}

Objectives Tofacitinib is a Janus kinase inhibitor for the treatment of rheumatoid arthritis (RA), psoriatic arthritis (PsA) and ulcerative colitis, and has been investigated in psoriasis (PsO). Routine pharmacovigilance of an ongoing, open-label, blinded-endpoint, tofacitinib RA trial (Study A3921133; NCT02092467) in patients aged $\geq 50$ years and with $\geq 1$ cardiovascular risk factor identified a higher frequency of pulmonary embolism $(P E)$ and all-cause mortality for patients receiving tofacitinib $10 \mathrm{mg}$ twice daily versus those receiving tumour necrosis factor inhibitors and resulted in identification of a safety signal for tofacitinib. Here, we report the incidence of deep vein thrombosis (DVT), $P E$, venous thromboembolism (VTE; DVT or PE) and arterial thromboembolism (ATE) from the tofacitinib RA (excluding Study A3921133), PsA and PsO development programmes and observational studies. Data from an ad hoc safety analysis of Study A3921133 are reported separately within.

Methods This post-hoc analysis used data from separate tofacitinib RA, PsO and PsA programmes. Incidence rates (IRs; patients with events per 100 patient-years' exposure) were calculated for DVT, PE, VTE and ATE, including for populations stratified by defined baseline cardiovascular or VTE risk factors. Observational data from the US Corrona registries (including cardiovascular risk factor stratification), IBM MarketScan research database and the US FDA Adverse Event Reporting System (FAERS) database were analysed. Results 12410 tofacitinib-treated patients from the development programmes (RA: $n=7964$;

PsO: $n=3663 ;$ PsA: $n=783$ ) were included. IRs (95\% CI) of thromboembolic events among the all tofacitinib cohorts' average tofacitinib $5 \mathrm{mg}$ and $10 \mathrm{mg}$ twice daily treated patients for RA, respectively, were: DVT $(0.17$ (0.09-0.27) and $0.15(0.09-0.22)) ;$ PE (0.12 (0.06$0.22)$ and $0.13(0.08-0.21)) ;$ ATE (0.32 (0.22-0.46) and $0.38(0.28-0.49))$. Among PsO patients, IRs were: DVT $(0.06(0.00-0.36)$ and $0.06(0.02-0.15)) ;$ PE $(0.13(0.02-0.47)$ and $0.09(0.04-0.19)) ;$ ATE (0.52 (0.22-1.02) and $0.22(0.13-0.35))$. Among PsA patients, IRs were: DVT (0.00 (0.00-0.28) and $0.13(0.00-0.70))$; PE (0.08 (0.00-0.43) and $0.00(0.00-0.46))$; ATE (0.31 (0.08-0.79) and $0.38(0.08-1.11))$. IRs were similar
Key messages

What is already known about this subject?

- The risk of venous thromboembolism (VTE) (including deep vein thrombosis (DVT) and pulmonary embolism (PE)) and arterial thromboembolism (ATE) is elevated in patients with immune-mediated inflammatory diseases such as rheumatoid arthritis (RA), psoriasis (PsO) and psoriatic arthritis (PsA). Labelling for the Janus kinase (JAK) inhibitors tofacitinib, baricitinib and upadacitinib now includes thrombosis as a warning and/or as an adverse drug reaction, with specific variations according to region, country and JAK inhibitor.

- In February 2019, a safety analysis of Study A3921133 (NCT02092467)—an ongoing, postauthorisation safety surveillance study in RA patients aged $\geq 50$ years and with $\geq 1$ cardiovascular risk factor-completed by the Data Safety Monitoring Board reported an increased incidence of PE events and all-cause mortality in patients treated with tofacitinib 10 mg twice daily versus tumour necrosis factor inhibitors.

- DVT and PE events have been observed in the tofacitinib ulcerative colitis programme (phase 2, 3 and open-label extension studies); incidence rates (IRs; patients with events per 100 patient-years' exposure) were 0.04 (95\% Cl $0-0.23)$ and $0.16(0.04-0.41)$, respectively.

between tofacitinib doses and generally higher in patients with baseline cardiovascular or VTE risk factors. IRs from the overall Corrona populations and in Corrona RA patients (including tofacitinib-naïve/biologic diseasemodifying antirheumatic drug-treated and tofacitinibtreated) with baseline cardiovascular risk factors were similar to IRs observed among the corresponding patients in the tofacitinib development programme. No signals of disproportionate reporting of DVT, PE or ATE with tofacitinib were identified in the FAERS database. Conclusions DVT, PE and ATE IRs in the tofacitinib RA, $\mathrm{PsO}$ and PsA programmes were similar across tofacitinib 
Key messages

\section{What does this study add?}

- Analysis of data from the tofacitinib RA (excluding Study A3921133), PsO and PsA programmes shows DVT, PE and ATE IRs to be higher in patients with defined baseline cardiovascular or VTE risk factors versus those without, and consistent with IRs in cardiovascular risk factor-enriched patients from observational data. IRs in patients with baseline cardiovascular risk factors in the RA programme were broadly comparable to those in the ad hoc safety analysis of Study A3921133, although the IR (95\% Cl) for PE was higher in patients treated with tofacitinib $10 \mathrm{mg}$ twice daily in Study A3921133 (0.54 (0.32-0.87)), versus patients with baseline cardiovascular risk factors treated with tofacitinib $10 \mathrm{mg}$ twice daily in the RA programme $(0.24(0.13-0.41))$.

\section{How might this impact on clinical practice or future} developments?

- VTE has been determined to be an important identified risk of tofacitinib treatment, and local labelling has been updated regarding risk factors for thromboembolism to reflect the ad hoc safety analysis of Study A3921133 and knowledge of the JAK inhibitor safety profile. Further research is needed to better understand the relationship between thromboembolic events and JAK inhibitors, including tofacitinib.

doses, and generally consistent with observational data and published IRs of other treatments. As expected, IRs of thromboembolic events were elevated in patients with versus without baseline cardiovascular or VTE risk factors, and were broadly consistent with those observed in the Study A3921133 ad hoc safety analysis data, although the IR $(95 \% \mathrm{Cl})$ for PE was greater in patients treated with tofacitinib $10 \mathrm{mg}$ twice daily in Study A3921133 (0.54 (0.32-0.87)), versus patients with baseline cardiovascular risk factors treated with tofacitinib $10 \mathrm{mg}$ twice daily in the RA programme (0.24 (0.13-0.41)).

\section{INTRODUCTION}

Tofacitinib is a Janus kinase (JAK) inhibitor for the treatment of rheumatoid arthritis (RA), psoriatic arthritis (PsA) and ulcerative colitis (UC), and has been investigated in psoriasis ( $\mathrm{PsO}$; approved for use in moderate to severe plaque $\mathrm{PsO}$ in Russia only). Labelling for the JAK inhibitors tofacitinib, ${ }^{12}$ baricitinib $^{34}$ and upadacitinib ${ }^{56}$ now includes thrombosis as a warning and/ or as an adverse drug reaction, with specific labelling varying by region or country, and by individual JAK inhibitor.

Inflammation is a risk factor for venous thromboembolism (VTE)-including deep vein thrombosis (DVT) and pulmonary embolism (PE) - and arterial thromboembolism (ATE).$^{7-9}$ Several attributes (including inflammatory diseases), family history, older age, Black race, smoking, hypertension, diabetes, cancer, hormone therapy, major surgical procedures, obesity and immobilisation are risk factors for VTE. ${ }^{79-17}$ Increased incidence of VTE and ATE relative to the general population has been reported in patients with immune-mediated inflammatory diseases, including $\mathrm{RA}^{18-30}{ }^{18} \mathrm{PsO}^{22} 242531-37$ and PsA. ${ }^{22} 3839$

An ongoing, randomised, open-label, blinded-endpoint (major adverse cardiovascular events (MACE) and malignancies excluding non-melanoma skin cancers), postauthorisation study in RA patients-Study A3921133 (ClinicalTrials.gov NCT02092467)— is evaluating the safety of tofacitinib $5 \mathrm{mg}$ twice daily and tofacitinib $10 \mathrm{mg}$ twice daily versus tumour necrosis factor inhibitors (TNFi) among patients with cardiovascular risk factors. ${ }^{40}$ In February 2019, during routine analysis of all safety events, the external, independent tofacitinib Rheumatology Data Safety Monitoring Board reported that, in the ongoing Study A3921133, among other findings, the frequency of PE and all-cause mortality in patients receiving tofacitinib $10 \mathrm{mg}$ twice daily was higher than in patients treated with a TNFi (full data set is not yet available). ${ }^{141}$

In order to better understand VTE and ATE in RA, PsO and PsA patients receiving tofacitinib, we present data from the overall $\mathrm{RA}, \mathrm{PsO}$ and PsA development programmes; this analysis also includes patients in the development programmes randomised to adalimumab and methotrexate. The incidence rates (IRs; 95\% CI) of DVT and PE in the tofacitinib UC programme have been previously reported $(0.04(0-0.23)$ and $0.16(0.04-0.41)$, respectively). ${ }^{42}$ We also report thrombotic events stratified by the presence or absence of elevated baseline cardiovascular risk (aligned as closely as possible with the inclusion criteria of Study A3921133, listed in the online supplementary text) and elevated VTE risk, measured at baseline (cardiovascular and VTE risk factors are listed in the methods), as well as the results of an ad hoc safety analysis of Study A3921133. Additional context for the observed IRs is provided through the reporting of observational data in RA, PsO and PsA patients from the US Corrona registries, IBM MarketScan research database and the US FDA Adverse Event Reporting System (FAERS) database.

\section{METHODS}

\section{Clinical data}

This was a posthoc analysis of safety data from phase 1 to 3 , $3 \mathrm{~b} / 4$ and long-term extension (LTE) clinical studies of tofacitinib in RA patients, from phase 2 to 3 and LTE studies of tofacitinib in PsO patients, and from phase 3 and LTE studies of tofacitinib in PsA patients. As Study A3921133 remains ongoing, its data were not included in these pooled analyses for any RA cohort; however, data from an ad hoc safety analysis are reported separately here (data have not yet been source-verified or subjected to standard quality-check procedures that would occur at the time of database lock, and may therefore be subject to change). ${ }^{1}$

Full details of study designs and inclusion/exclusion criteria for each completed study have previously been published (online supplementary table S1). The ongoing Study A3921133 (NCT02092467; data cut-off February 2019; database not locked; data have not yet been source-verified or subjected to standard quality-check procedures that would occur at the time of database lock, and may therefore be subject to change) has enrolled patients aged $\geq 50$ years and with $\geq 1$ cardiovascular risk factor, receiving a stable dose of methotrexate (cardiovascular risk factors and inclusion/exclusion criteria are reported in the online supplementary material). Studies were conducted in accordance with the Declaration of Helsinki, the International Conference on Harmonization Guidelines for Good Clinical Practice, and local regulations.

RA patients received tofacitinib immediate-release twice daily or in a modified-release formulation (once daily) either as monotherapy or in combination with conventional synthetic diseasemodifying antirheumatic drugs (csDMARDs); all PsA patients received tofacitinib immediate-release twice daily in combination with one csDMARD; all $\mathrm{PsO}$ patients received tofacitinib immediate-release twice daily as monotherapy.

Three posthoc analysis cohorts were defined for each of the three separate programmes (RA, PsO and PsA): placebo-controlled cohort, dose-comparison and active-control cohort and all 
tofacitinib cohort; further details on each cohort are given in the online supplementary material. The placebo-controlled cohort included patients randomised to tofacitinib 5 or $10 \mathrm{mg}$ twice daily or placebo up to month 3 (before any placebo-treated patients advanced to tofacitinib). The dose-comparison and active-control cohort included data from patients treated for $\leq 24$ months for RA and $\leq 12$ months for $\mathrm{PsO}$ and PsA, randomised to tofacitinib 5 or $10 \mathrm{mg}$ twice daily (including those who advanced from placebo in the PsO and PsA programmes), adalimumab $40 \mathrm{mg}$ subcutaneous once every 2 weeks (active control in one phase 2 RA study, one phase 3 RA study and one phase 3 PsA study; active comparator in one phase $3 / 4 \mathrm{~b}$ RA study), or methotrexate $\leq 20 \mathrm{mg}$ once weekly (comparator in one phase 2 and one phase 3 RA study). The all tofacitinib cohort encompassed all patients in each disease programme who received $\geq 1$ dose of tofacitinib (primarily 5 or 10 mg twice daily or $11 \mathrm{mg}$ once daily) in RA ( $\leq 114$ months' tofacitinib exposure; final data as of 18 January 2019), $\mathrm{PsO}$ ( $\leq 66$ months' tofacitinib exposure; final data as of 18 August 2016) and PsA ( $\leq 62$ months' tofacitinib exposure; final data as of 31 July 2019) studies.

For the RA, PsO and PsA all tofacitinib cohort, dose group was categorised using two methods, as patients could change doses between the index and LTE studies, and within the LTE studies. For the average-dosing algorithm, patients were assigned to average tofacitinib 5 or $10 \mathrm{mg}$ twice daily if the average total daily dose over the course of observation was $<15$ or $\geq 15 \mathrm{mg}$, respectively. For the constant-dosing algorithm, only patients exposed to a constant tofacitinib dose of 5 or $10 \mathrm{mg}$ twice daily without prior exposure to a different tofacitinib dose or adalimumab were included in the algorithm; exposure and events captured after a dose switch were excluded from the constant-dose analysis.

Data were not pooled across RA, PsO and PsA. In the described posthoc analysis of the three cohorts, all available patient-level data was used, with no exclusion criteria applied specifically related to VTE or ATE.

Additional analyses within the pooled RA, PsO and PsA clinical trial data sets were conducted. Patients were stratified by the presence or absence of defined baseline cardiovascular or VTE risk factors. Patients were identified as having cardiovascular risk factors at baseline if they were aged $\geq 50$ years and met $\geq 1$ of the following criteria: current smoker, high-density lipoprotein (HDL) $<40 \mathrm{mg} / \mathrm{dL}$, history of hypertension diagnosis, history of diabetes diagnosis, history of myocardial infarction or history of coronary heart disease diagnosis; this definition of cardiovascular risk factors is similar to that used in the inclusion criteria of Study A3921133 $3^{140}$ and a recently completed trial of a TNFi (etanercept) versus an interleukin-6 inhibitor (tocilizumab) in RA patients with cardiovascular risk factors (ENTRACTE) ${ }^{43}$ For the purposes of this analysis, patients were identified as having VTE risk factors if they met any of the following criteria at baseline: aged $\geq 60$ years, current smoker, previous heart failure, previous VTE (DVT or PE), body mass index (BMI) $\geq 30 \mathrm{~kg} / \mathrm{m}^{2}$, Day 1 use of oral contraceptives or hormone replacement therapy, Day 1 use of antidepressants or Day 1 use of aspirin. Please note that this definition of VTE risk factors is specific to this analysis and reflects available data from the clinical trials; for this reason, it may differ to definitions used elsewhere.

DVT, PE and ATE events were identified using the Medical Dictionary for Regulatory Activities (MedDRA) selected (clinically relevant) Preferred Terms (PTs) from the Standardised MedDRA Queries (SMQs) Embolic and thrombotic events, venous and Embolic and thrombotic events, arterial (including PT for cases of myocardial infarction and ischaemic stroke). Given the potential that some PTs, consistent with DVT and ATE, are not included in the above SMQs, the database was also examined for clinically relevant terms for the SMQ Embolic and thrombotic events, vessel type unspecified and mixed arterial and venous. Details are given in the online supplementary material. PTs were based on spontaneous reporting of adverse events by investigators and were not corroborated or confirmed by any protocol-mandated assessment or activity.

IRs were calculated as the number of patients with an event per 100 patient-years (PY) of exposure, defined as time to first event occurring during the risk period (minimum of a patient's last treatment dose date plus 28 days, date of death or up to the last observation date). Poisson 95\% CIs for the IRs were calculated.

Separate IRs were calculated for DVT, PE and ATE events (including both outpatient and inpatient events), and for VTE (a composite of the first DVT or PE event). Patients who experienced more than one event were censored at the time of first event. For patients who experienced multiple events at the same time, each event was included in the DVT, PE and ATE IR estimates, respectively. For VTE event (DVT or PE) IR estimates, the patient was only included once, even if there was simultaneous reporting of DVT and PE in the same patient.

Kaplan-Meier analysis was performed for time to DVT, PE or ATE; total follow-up time was calculated up to the day of the first event (subject to the above risk period).

\section{Observational/postmarketing data}

For all observational data from the relevant US Corrona registries and MarketScan database, the IRs were calculated as patients with events per 100 PY of exposure (Corrona) or as events per 100 PY of exposure (MarketScan). Rates were standardised by age and sex distribution for each disease in the tofacitinib programme, unless otherwise stated (details given in the online supplementary material).

Data were obtained from the US Corrona registries ${ }^{44}$ for RA, $\mathrm{PsO}$ or PsA patients who received non-biologic or biologic treatments (online supplementary table S2) from 6 November 2012 for RA, 1 April 2015 for PsO or 1 March 2013 for PsA, up to 31 December 2017. Exposure time was defined as the time in years from the index date (first date of prescription or administration of approved treatment after diagnosis) to the first VTE event (DVT or PE), last follow-up visit, or switch to tofacitinib, whichever came first.

An additional subanalysis within the RA Corrona-based postauthorisation safety study of tofacitinib ${ }^{45}$ investigated the incidence of DVT and PE events in cohorts of patients with moderate to severe RA (Clinical Disease Activity Index (CDAI) $>10$ at initiation) initiating a biologic disease-modifying antirheumatic drug (bDMARD) or tofacitinib, who were aged $\geq 50$ years and had $\geq 1$ cardiovascular risk factor (details in the online supplementary material). Non-standardised/unadjusted (crude) IRs were calculated. The time to first DVT or PE event was also calculated.

Data were also obtained and analysed from the IBM MarketScan research database (hereafter MarketScan database) ${ }^{46}$ for RA, PsO or PsA patients treated between 1 January 2010 and 31 December 2017 (online supplementary material). Exposure time was defined as the time in years from the index date to the first DVT or PE event, identified using ICD9/10 diagnosis codes and patient medication use.

Using the FAERS database, disproportionality analyses were performed on spontaneous reports to assess if there was a signal of disproportionate reporting (SDR) through analysis of observedto-expected $(\mathrm{O} / \mathrm{E})$ reporting frequencies. Analyses were completed for the identified events of Embolic and thrombotic events, venous, Embolic and thrombotic events, arterial and Embolic and thrombotic events, vessel type unspecified and mixed arterial and venous 
SMQs reported in association with tofacitinib. For the shrinkageadjusted $\mathrm{O} / \mathrm{E}$, an SDR was defined as a lower 5\% bound of the $90 \%$ interval of the shrinkage-adjusted $\mathrm{O} / \mathrm{E}$ ratio $\left(\mathrm{EB}_{05}\right)>2 .{ }^{47}$ For the unadjusted metric, an SDR was defined as the lower 5\% bound of the $90 \%$ interval of the reporting odds ratio $\left(\mathrm{ROR}_{05}\right)>2$ and $\mathrm{a}$ minimum case count $>2$.

\section{Patient and public involvement}

Patients and the public were not involved in the design, analysis or results interpretation of this study. Patient-level data from the relevant data sets were used to complete the analysis.

\section{RESULTS \\ Tofacitinib clinical trials}

Patients

Overall, 12410 tofacitinib-exposed patients from completed studies in the development programmes were included in this analysis: 7964 with RA, 3663 with PsO and 783 with PsA. Table 1 summarises demographics and baseline characteristics for all patients who received $\geq 1$ dose of tofacitinib. Online supplementary tables S3-5 summarise the demographics and baseline characteristics data, stratified by the presence or absence of baseline cardiovascular or VTE risk factors.

\section{Incidence of VTE and ATE: placebo-controlled cohort}

During the first 90 days of tofacitinib treatment (up to month 3 in the placebo-controlled cohorts), the IRs of DVT, PE, VTE (DVT or PE) and ATE events were similar between tofacitinib doses and placebo across each of the RA (figure 1), PsO (figure 2) and PsA (figure 3) development programmes.

One patient with RA receiving placebo experienced both a DVT and a PE event; this patient was aged $>50$ years and had multiple risk factors, including current smoker, medical history of thrombosis and Day 1 use of hormone replacement therapy and antidepressants.

\section{Incidence of VTE and ATE: dose-comparison and active-control cohort}

In RA up to month 24, and in PsO and PsA up to month 12, IRs of DVT, PE, VTE (DVT or PE) and ATE events were similar between tofacitinib (both doses), adalimumab and methotrexate (figures 1-3).

Incidence of VTE and ATE: all tofacitinib cohort-all patients Among RA (figure 1), PsO (figure 2) and PsA (figure 3) patients, the IRs of all events were similar for average tofacitinib 5 and $10 \mathrm{mg}$ twice daily. Among RA patients, IRs for constant tofacitinib $10 \mathrm{mg}$ twice daily were similar to those for constant tofacitinib $5 \mathrm{mg}$ twice daily.

Analysis of Kaplan-Meier curves, showing proportions of RA patients in the tofacitinib development programme without a thromboembolic event, did not reveal any separation between dose groups, and most events occurred during the LTE. More events occurring during the LTE can be attributed to the longer observation time in the LTE versus the index studies. Further, the curves indicated a consistent rate of event occurrence over time (online supplementary figure S1). Thromboembolic events among $\mathrm{PsO}$ and PsA patients were too few to be represented in Kaplan-Meier curves.

Analysis of the SMQ Embolic and thrombotic events, vessel type unspecified and mixed arterial and venous - to identify additional PTs consistent with VTE/ATE-revealed one patient each with cerebral thrombosis (RA programme; average $5 \mathrm{mg}$ twice daily), intracardiac thrombus (RA programme; average $10 \mathrm{mg}$ twice daily) and thrombotic stroke (PsO programme; average $10 \mathrm{mg}$ twice daily). These events were not included in the IR calculations.

Incidence of VTE and ATE: all tofacitinib cohort-stratified by

baseline cardiovascular or VTE risk factors

The IRs of DVT, PE, VTE (DVT or PE) and ATE were generally higher in patients with a baseline cardiovascular or VTE risk factor versus patients without (figures 1-3). IRs were lower in RA patients without risk factors $(61 \%$ with no cardiovascular risk factors; 34\% with no VTE risk factors) versus those with risk factors. Among PsA patients, all DVT and PE events were experienced by patients who had baseline cardiovascular or VTE risk factors. However, across all diseases, comparison of thromboembolic event IRs in patients with baseline cardiovascular or VTE risk was limited by the low number of events and did not illustrate meaningful differences across groups.

IRs were similar between average tofacitinib 5 and $10 \mathrm{mg}$ twice daily among patients with cardiovascular or VTE risk factors (figures 1-3). For RA patients without cardiovascular or VTE risk factors, IRs of DVT, PE and VTE (but not ATE) were modestly numerically higher for average tofacitinib $10 \mathrm{mg}$ twice daily relative to average tofacitinib $5 \mathrm{mg}$ twice daily, but the number of events across all diseases in patients without risk factors was too low to draw firm conclusions.

Incidence of DVT and PE: Study A3921133 (ad hoc safety analysis) The ongoing Study A3921133 includes 4362 randomised patients, and is accruing safety and efficacy data as specified per study protocol. ${ }^{40}$ Patient demographics and baseline characteristics were balanced across treatment arms, and the patient population in Study A3921133 is generally consistent with the cardiovascular risk factor-enriched patient population from the RA programme (Pfizer data on file).

IRs $(95 \% \mathrm{CI})$ in an ad hoc safety analysis of the ongoing Study A3921133 (NCT02092467; data cut-off February 2019; database not locked; data have not yet been source-verified or subjected to standard quality-check procedures that would occur at the time of database lock, and may therefore be subject to change) for DVT and PE with tofacitinib $5 \mathrm{mg}$ twice daily, tofacitinib $10 \mathrm{mg}$ twice daily and TNFi are reported in figure $4 .{ }^{1}$ Compared with TNFi, the hazard ratios (HRs) (95\% CI) for DVT/PE with tofacitinib $5 \mathrm{mg}$ twice daily were $1.66(0.60-$ 4.57)/2.99 (0.81-11.06), and 2.13 (0.80-5.69)/5.96 (1.7520.33) with tofacitinib $10 \mathrm{mg}$ twice daily. ${ }^{1}$

\section{Baseline risk factor analysis}

When the individual baseline risk factors for each patient who experienced DVT, PE or ATE in completed studies of the tofacitinib development programmes were evaluated, the most common baseline risk factors in RA patients were C-reactive protein level (CRP) $>2.87 \mathrm{mg} / \mathrm{L}$, hypertension, aged $\geq 60$ years and Day 1 use of corticosteroids; in PsO patients, CRP $>2.87 \mathrm{mg} / \mathrm{L}$, male sex and $\mathrm{BMI} \geq 30 \mathrm{~kg} / \mathrm{m}^{2}$ appeared to be the most common baseline risk factors; events among PsA patients were too low to draw conclusions (online supplementary table S6). It should be noted that active disease was an inclusion criteria for the RA studies, with patients requiring either an erythrocyte sedimentation rate $>28 \mathrm{~mm} /$ hour or $\mathrm{CRP}>7 \mathrm{mg} / \mathrm{L}$. The vast majority of patients who experienced a thromboembolic event had multiple baseline risk factors (figure 5). 
Table 1 Patient demographics and baseline characteristics for all tofacitinib-treated patients (all tofacitinib cohort) in completed studies in the $\mathrm{RA}, \mathrm{PsO}$ and PsA development programmes, stratified by average tofacitinib dose*

\begin{tabular}{|c|c|c|c|c|c|c|}
\hline & \multicolumn{2}{|l|}{ RA } & \multicolumn{2}{|l|}{ PsO } & \multicolumn{2}{|l|}{ PsA } \\
\hline & $\begin{array}{l}\text { Average tofacitinib } \\
5 \mathrm{mg} \\
\text { twice daily } \\
(\mathrm{N}=3969)\end{array}$ & $\begin{array}{l}\text { Average tofacitinib } \\
10 \mathrm{mg} \text { twice daily } \\
(\mathrm{N}=3995)\end{array}$ & $\begin{array}{l}\text { Average tofacitinib } \\
5 \mathrm{mg} \\
\text { twice daily } \\
(\mathrm{N}=920)\end{array}$ & $\begin{array}{l}\text { Average tofacitinib } \\
10 \mathrm{mg} \text { twice daily } \\
(\mathrm{N}=2743)\end{array}$ & $\begin{array}{l}\text { Average tofacitinib } \\
5 \mathrm{mg} \\
\text { twice daily } \\
(\mathrm{N}=458)\end{array}$ & $\begin{array}{l}\text { Average tofacitinib } \\
10 \mathrm{mg} \text { twice daily } \\
(\mathrm{N}=325)\end{array}$ \\
\hline Age (years), mean (SD) & $53.3(12.4)$ & $52.0(11.6)$ & $45.5(13.3)$ & 44.5 (12.7) & $49.2(11.9)$ & $48.0(12.2)$ \\
\hline$\geq 65$ years of age, $n(\%)$ & $722(18.2)$ & $548(13.7)$ & $71(7.7)$ & $149(5.4)$ & $42(9.2)$ & $30(9.2)$ \\
\hline$\geq 50$ years of age, $n(\%)$ & $2606(65.7)$ & $2481(62.1)$ & $386(42.0)$ & $1015(37.0)$ & $238(52.0)$ & $160(49.2)$ \\
\hline Female, n (\%) & $3236(81.5)$ & $3286(82.3)$ & $323(35.1)$ & $794(28.9)$ & $258(56.3)$ & $170(52.3)$ \\
\hline \multicolumn{7}{|l|}{ Race, n (\%) } \\
\hline White & $2417(60.9)$ & $2753(68.9)$ & $794(86.3)$ & $2341(85.3)$ & $434(94.8)$ & $305(93.8)$ \\
\hline Black & $121(3.0)$ & $131(3.3)$ & $27(2.9)$ & $51(1.9)$ & $0(0)$ & $3(0.9)$ \\
\hline Asian & $1126(28.4)$ & $686(17.2)$ & $42(4.6)$ & $207(7.5)$ & $11(2.4)$ & $12(3.7)$ \\
\hline Other/unknown & $305(7.7)$ & $425(10.6)$ & $57(6.2)$ & $144(5.2)$ & $13(2.8)$ & $5(1.5)$ \\
\hline $\begin{array}{l}\text { BMI }\left(\mathrm{kg} / \mathrm{m}^{2}\right) \text {, mean (SD) } \\
\text { (N1) }\end{array}$ & $26.7(6.2)(3961)$ & $27.5(6.5)(3993)$ & 29.7 (6.5) (919) & $29.9(6.8)(2740)$ & 29.5 (5.9) (458) & $29.8(6.2)(325)$ \\
\hline $\begin{array}{l}\mathrm{BMI} \geq 30 \mathrm{~kg} / \mathrm{m}^{2}, \mathrm{n}(\%) \\
\text { (N1) }\end{array}$ & $982(24.8)(3961)$ & $1156(29.0)(3993)$ & 384 (41.8) (919) & $1160(42.3)(2740)$ & $196(42.8)(458)$ & $137(42.2)(325)$ \\
\hline \multicolumn{7}{|l|}{ Smoking status, n (\%) } \\
\hline Never smoked & $2522(63.5)$ & 2474 (61.9) & $353(38.4)$ & 1059 (38.6) & $289(63.1)$ & $196(60.3)$ \\
\hline Smoker & $648(16.3)$ & $718(18.0)$ & $365(39.7)$ & $1015(37.0)$ & $92(20.1)$ & $48(14.8)$ \\
\hline Ex-smoker & $689(17.4)$ & $699(17.5)$ & $202(22.0)$ & $669(24.4)$ & 77 (16.8) & $81(24.9)$ \\
\hline Unknown & $110(2.8)$ & $104(2.6)$ & 0 & 0 & 0 & 0 \\
\hline \multicolumn{7}{|l|}{ Comorbidities, n (\%) } \\
\hline Diabetes & $365(9.2)$ & $286(7.2)$ & $128(13.9)$ & $371(13.5)$ & $61(13.3)$ & $46(14.2)$ \\
\hline Hypertension & $1405(35.4)$ & $1413(35.4)$ & $219(23.8)$ & $595(21.7)$ & $180(39.3)$ & $119(36.6)$ \\
\hline $\begin{array}{l}\text { Coronary heart } \\
\text { disease }\end{array}$ & $13(0.3)$ & $17(0.4)$ & $24(2.6)$ & $66(2.4)$ & $23(5.0)$ & $16(4.9)$ \\
\hline Myocardial infarction & $50(1.3)$ & $50(1.3)$ & $8(0.9)$ & $24(0.9)$ & $6(1.3)$ & $9(2.8)$ \\
\hline $\begin{array}{l}\text { History of } \\
\text { hyperlipidemia, n (\%) }\end{array}$ & $740(18.6)$ & $794(19.9)$ & $220(23.9)$ & $641(23.4)$ & $94(20.5)$ & $73(22.5)$ \\
\hline $\begin{array}{l}\text { Previous heart failure, } \\
\mathrm{n}(\%)\end{array}$ & $28(0.7)$ & $14(0.4)$ & 0 & $7(0.3)$ & 0 & $3(0.9)$ \\
\hline $\begin{array}{l}\text { Previous VTE (DVT or } \\
\text { PE), } n(\%)\end{array}$ & $40(1.0)$ & $48(1.2)$ & $2(0.2)$ & $9(0.3)$ & $3(0.7)$ & $7(2.2)$ \\
\hline $\begin{array}{l}\text { CRP > } 2.87 \text { mg/L, n (\%) } \\
\text { (N1) }\end{array}$ & $3158(80.2)(3939)$ & $3188(80.5)(3958)$ & $378(47.0)(804)$ & $1119(48.7)(2297)$ & $288(62.9)(458)$ & $198(60.9)(325)$ \\
\hline \multicolumn{7}{|c|}{ Concomitant medication, $\mathrm{n}(\%)$} \\
\hline Steroids & $2070(52.2)$ & $2184(54.7)$ & $0 \dagger$ & $0+$ & $109(23.8)$ & $62(19.1)$ \\
\hline Anticoagulants & $316(8.0)$ & $344(8.6)$ & $75(8.2)$ & $188(6.9)$ & $34(7.4) \ddagger$ & $34(10.5) \ddagger$ \\
\hline Antiplatelet agents & $280(7.1)$ & $339(8.5)$ & $78(8.5)$ & $194(7.1)$ & $31(6.8) \ddagger$ & $23(7.1) \ddagger$ \\
\hline OCT or HRT $\ddagger$ & $347(8.7)$ & $334(8.4)$ & $75(0.2)$ & $186(6.8)$ & $40(8.7)$ & $37(11.4)$ \\
\hline Antidepressants $\ddagger$ & $278(7.0)$ & $367(9.2)$ & $54(5.9)$ & $132(4.8)$ & $56(12.2)$ & $37(11.4)$ \\
\hline Statins $¥$ & $182(4.6)$ & $438(11.0)$ & $127(13.8)$ & $360(13.1)$ & $58(12.7)$ & $42(12.9)$ \\
\hline Aspirin & $246(6.2)$ & $305(7.6)$ & $70(7.6)$ & $172(6.3)$ & $28(6.1) \ddagger$ & $22(6.8) \ddagger$ \\
\hline Prior MTX use, n (\%) & $3610(91.0)$ & 3047 (76.3) & $276(30.0)$ & $881(32.1)$ & $432(94.3)$ & $293(90.2)$ \\
\hline $\begin{array}{l}\text { Prior csDMARD use } \\
\text { (other than MTX), } n(\%)\end{array}$ & 1655 (41.7) & $2084(52.2)$ & $83(9.0)$ & $307(11.2)$ & $205(44.8)$ & $165(50.8)$ \\
\hline Prior TNFi use, $\mathrm{n}(\%)$ & $463(11.7)$ & $782(19.6)$ & $140(15.2)$ & $440(16.0)$ & $190(41.5)$ & $187(57.5)$ \\
\hline $\begin{array}{l}\text { Prior non-TNFi bDMARD } \\
\text { use, } \mathrm{n}(\%)\end{array}$ & $177(4.5)$ & $237(5.9)$ & $53(5.8)$ & $161(5.9)$ & $24(5.2)$ & $22(6.8)$ \\
\hline
\end{tabular}

*Patients were assigned to average tofacitinib 5 or $10 \mathrm{mg}$ twice daily if the average total daily dose over the course of observation was $<15 \mathrm{or} \geq 15 \mathrm{mg}$, respectively.

tConcomitant steroids were not allowed in PsO trials.

‡Day 1 use.

DDMARD, biologic disease-modifying antirheumatic drug; BMI, body mass index; CRP, C-reactive protein; CSDMARD, conventional synthetic disease-modifying antirheumatic drug; DVT, deep vein thrombosis; HRT, hormone replacement therapy; MTX, methotrexate; n, number of patients with characteristic; N1, total number of patients for that characteristic;

$\mathrm{N}$, total number of patients; OCT, oral contraceptives; PE, pulmonary embolism; PsA, psoriatic arthritis; PsO, psoriasis; RA, rheumatoid arthritis; SD, standard deviation; TNFi,

tumour necrosis factor inhibitor; VTE, venous thromboembolism (DVT or PE). 

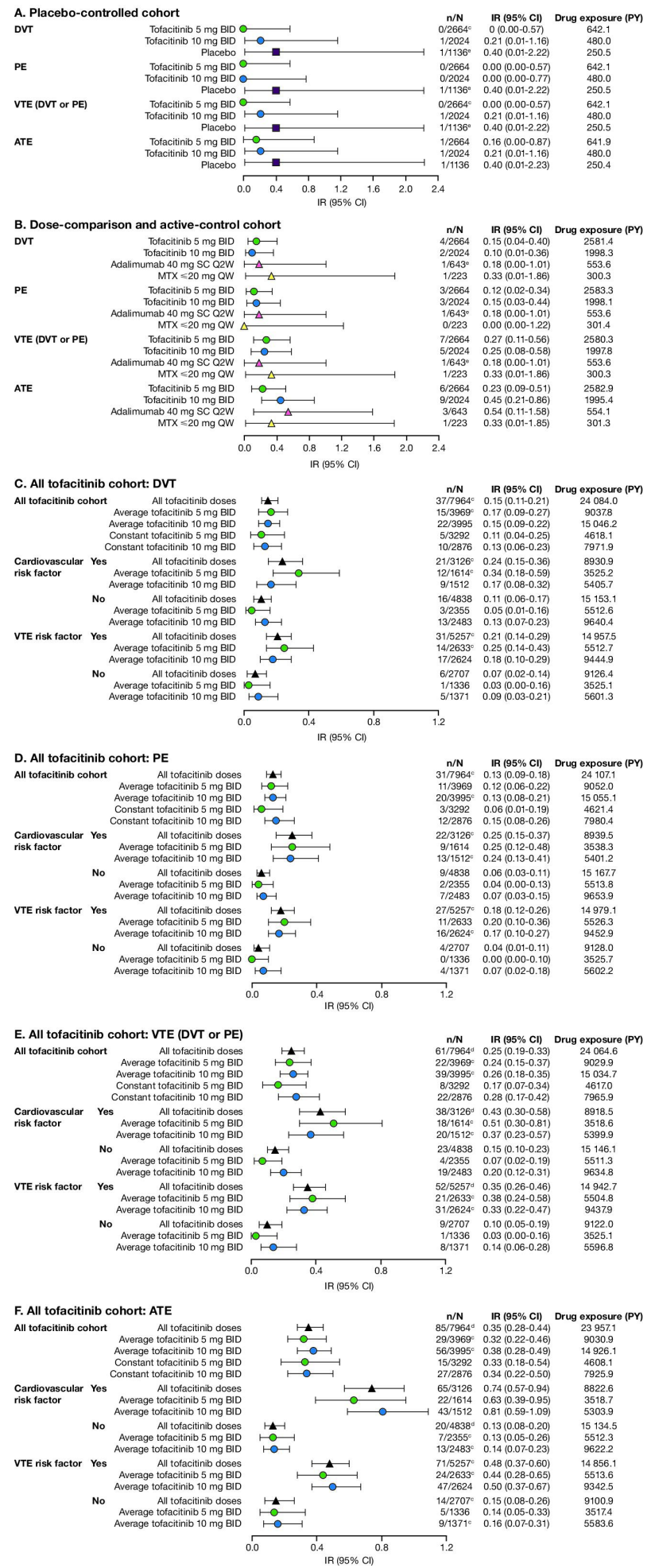

Figure 1 Drug exposure and incidence rates $(95 \% \mathrm{Cl})$ among RA patients in completed studies in the tofacitinib development programme for (A) the placebo-controlled cohort, (B) the dose-comparison and active-control cohort, and the all tofacitinib cohort for (C) DVT, (D) PE, (E) VTE (DVT or PE) and (F) ATE, including patients stratified by baseline cardiovascular ${ }^{\mathrm{a}}$ or VTE ${ }^{\mathrm{b}}$ risk factors; final data as of 18 January 2019. ${ }^{\mathrm{B} B a s e l i n e}$ cardiovascular risk factors were defined as any patient aged $\geq 50$ years and meeting $\geq 1$ of the following criteria at baseline: current smoker, $\mathrm{HDL}<40 \mathrm{mg} / \mathrm{dL}$, history of hypertension diagnosis, history of diabetes diagnosis, history of myocardial infarction or history of coronary heart disease diagnosis. ${ }^{b}$ Baseline VTE risk factors were defined as any patient meeting any of the following criteria at baseline: aged $\geq 60$ years, current smoker, previous heart failure, previous VTE (DVT or PE), BMI $\geq 30 \mathrm{~kg} / \mathrm{m}^{2}$, Day 1 use of oral contraceptives or hormone replacement therapy, Day 1 use of antidepressants or Day 1 use of aspirin. 'One or ${ }^{d}$ two patients were not counted in the numerator of the IR calculations because the events occurred outside the defined risk period. ${ }^{e}$ One patient experienced both DVT and PE. ATE, arterial thromboembolism; BID, twice daily; BMI, body mass index; DVT, deep vein thrombosis; HDL, high-density lipoprotein; IR, incidence rate (number of patients with an event per 100 PY of exposure); MTX, methotrexate; N, total number of patients; $n$, number of patients with an event; PE, pulmonary embolism; PY, patient-years; QW, once a week; Q2W, once every 2 weeks; RA, rheumatoid arthritis; SC, subcutaneous; VTE, venous thromboembolism. 

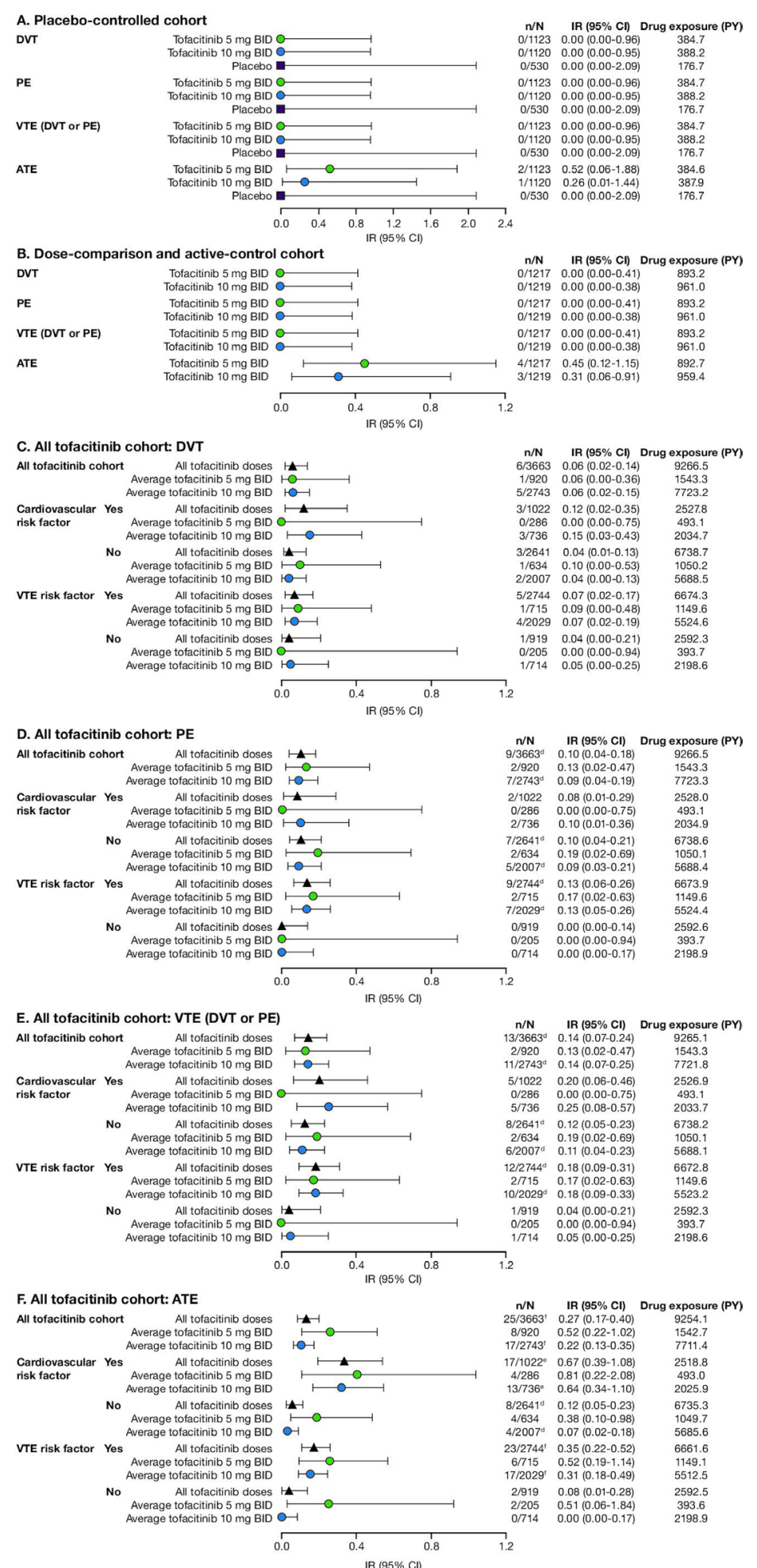

Figure 2 Drug exposure and incidence rates $(95 \% \mathrm{Cl})$ among PsO patients in completed studies in the tofacitinib development programme for (A) the placebo-controlled cohort, (B) the dose-comparison and active-control cohort, and the all tofacitinib cohort for (C) DVT, (D) PE, (E) VTE (DVT or PE) and (F) ATE, including patients stratified by baseline cardiovascular ${ }^{b}$ or VTE ${ }^{c}$ risk factors; final data as of 18 August 2016. ${ }^{2}$ The dose-comparison and active-control cohort includes patients receiving tofacitinib after switching from placebo. ${ }^{b}$ Baseline cardiovascular risk factors were defined as any patient aged $\geq 50$ years and meeting $\geq 1$ of the following criteria at baseline: current smoker, $\mathrm{HDL}<40 \mathrm{mg} / \mathrm{dL}$, history of hypertension diagnosis, history of diabetes diagnosis, history of myocardial infarction or history of coronary heart disease diagnosis. 'Baseline VTE risk factors were defined as any patient meeting any of the following criteria at baseline: aged $\geq 60$ years, current smoker, previous heart failure, previous VTE (DVT or PE), $\mathrm{BMI} \geq 30 \mathrm{~kg} / \mathrm{m}^{2}$, Day 1 use of oral contraceptives or hormone replacement therapy, Day 1 use of antidepressants or Day 1 use of aspirin. ${ }^{\mathrm{d}}$ One, ${ }^{e}$ three or four patients were not counted in the numerators of the IR calculations because the events occurred outside the defined risk period. ATE, arterial thromboembolism; BID, twice daily; BMI, body mass index; DVT, deep vein thrombosis; HDL, high-density lipoprotein; IR, incidence rate (number of patients with an event per $100 \mathrm{PY}$ of exposure); $\mathrm{N}$, total number of patients; $\mathrm{n}$, number of patients with an event; $\mathrm{PE}$, pulmonary embolism; PsO, psoriasis; PY, patient-years; VTE, venous thromboembolism. 

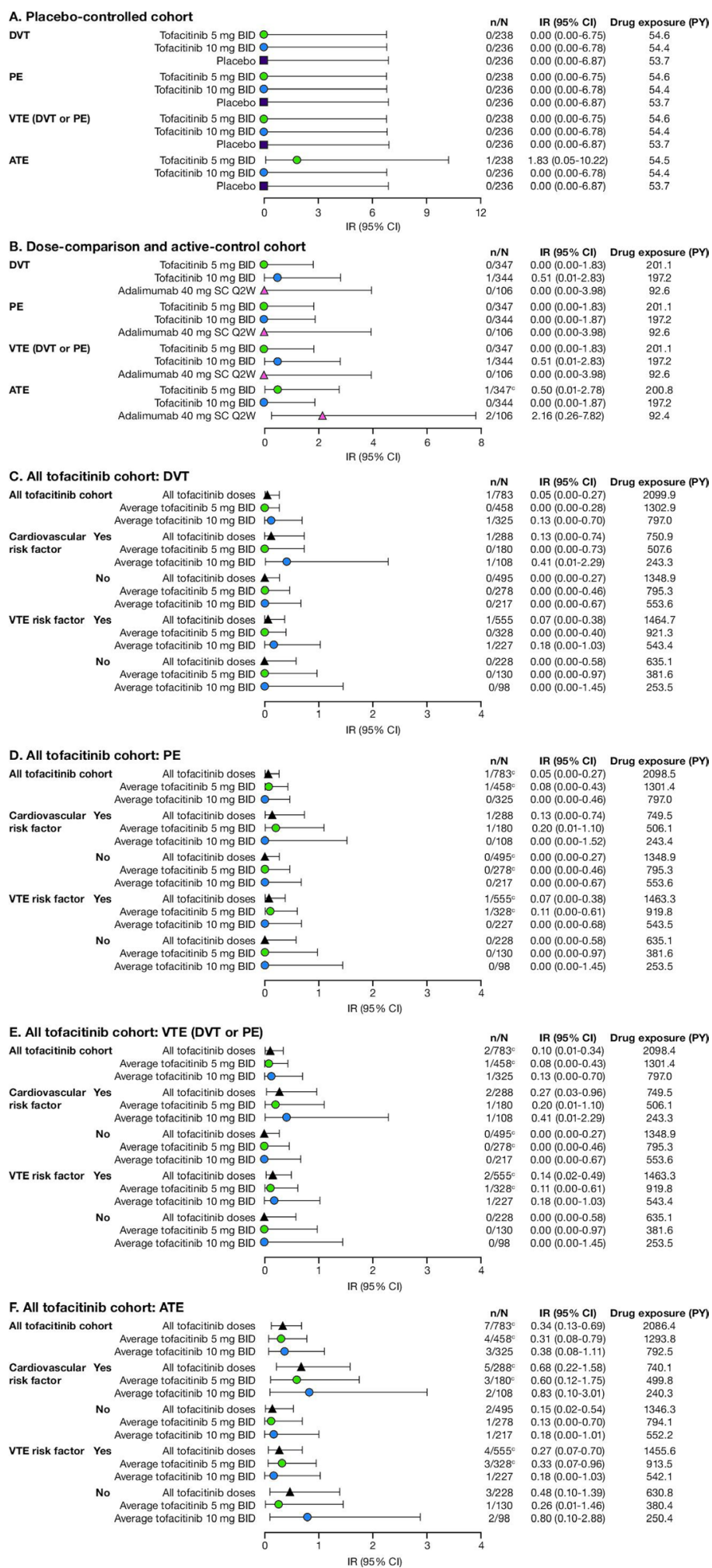

Figure 3 Drug exposure and incidence rates $(95 \% \mathrm{Cl})$ among PsA patients in completed studies in the tofacitinib development programme for (A) the placebo-controlled cohort, (B) the dose-comparison and active-control cohort, and the all tofacitinib cohort for (C) DVT, (D) PE, (E) VTE (DVT or $\mathrm{PE}$ ) and (F) ATE, including patients stratified by baseline cardiovascular ${ }^{\mathrm{a}}$ or VTE ${ }^{\mathrm{b}}$ risk factors; final data as of 31 July 2019 . ${ }^{\mathrm{a}}$ Baseline cardiovascular risk factors were defined as any patient aged $\geq 50$ years and meeting $\geq 1$ of the following criteria at baseline: current smoker, $\mathrm{HDL}<40 \mathrm{mg} / \mathrm{dL}$, history of hypertension diagnosis, history of diabetes diagnosis, history of myocardial infarction or history of coronary heart disease diagnosis. ${ }^{b}$ Baseline VTE risk factors were defined as any patient meeting any of the following criteria at baseline: aged $\geq 60$ years, current smoker, previous heart failure, previous VTE (DVT or PE), BMI $\geq 30 \mathrm{~kg} / \mathrm{m}^{2}$, Day 1 use of oral contraceptives or hormone replacement therapy, Day 1 use of antidepressants or Day 1 use of aspirin. 'One patient was not counted in the numerators of the IR calculations because the event occurred outside the defined risk period. ATE, arterial thromboembolism; BID, twice daily; BMI, body mass index; DVT, deep vein thrombosis; HDL, high-density lipoprotein; IR, incidence rate (number of patients with an event per $100 \mathrm{PY}$ of exposure); $\mathrm{N}$, total number of patients; $\mathrm{n}$, number of patients with an event; PE, pulmonary embolism; PsA, psoriatic arthritis; PY, patient-years; Q2W, once every 2 weeks; SC, subcutaneous; VTE, venous thromboembolism. 


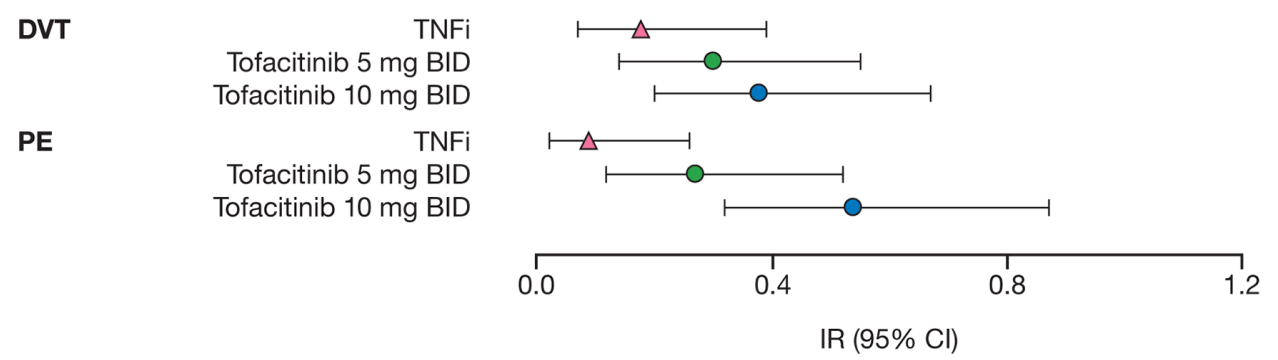

$0.18(0.07-0.39)$

$0.30(0.14-0.55)$

$0.38(0.20-0.67)$

$0.09(0.02-0.26)$

$0.27(0.12-0.52)$

$0.54(0.32-0.87)$

IR $(95 \% \mathrm{Cl})$

Figure 4 Incidence rates $\left(95 \%\right.$ Cl) for DVT and PE among patients in Study A3921133 (ad hoc safety analysis). ${ }^{\text {a1 }}$ Data cut-off February 2019; database not locked. Data have not yet been source-verified or subjected to standard quality-check procedures that would occur at the time of database lock, and may therefore be subject to change. BID, twice daily; DVT, deep vein thrombosis; IR, incidence rate (number of patients with an event per 100 PY of exposure); PE, pulmonary embolism; PY, patient-years; TNFi, tumour necrosis factor inhibitor.
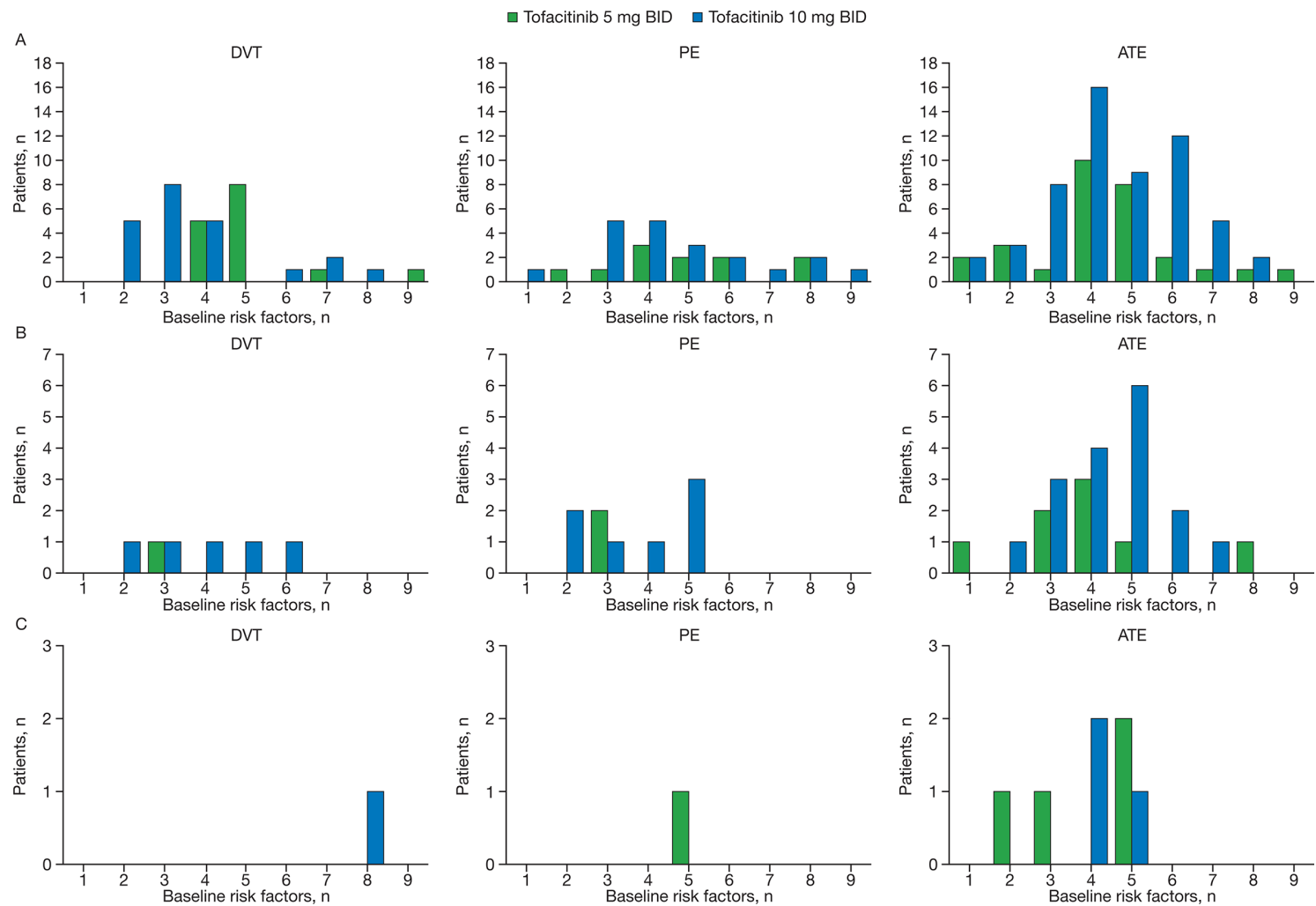

Figure 5 Number of baseline risk factors for patients who experienced a DVT, PE or ATE in completed studies in the (A) RA, (B) PsO and (C) PsA tofacitinib development programmes, stratified by tofacitinib dose. Those patients who had an event within the predefined risk period (minimum of a patient's last treatment dose date plus 28 days, date of death or up to the last observation date) are included. Details on the individual risk factors, and the number of patients who experienced each risk factor, are summarised in online supplementary table S6. ATE, arterial thromboembolism; BID, twice daily; DVT, deep vein thrombosis; n, number of patients with a given number of baseline risk factors; PE, pulmonary embolism; PsA, psoriatic arthritis; PsO, psoriasis; RA, rheumatoid arthritis.

\section{Comparison of clinical data and observational data}

Patient demographics and baseline characteristics were generally similar between the tofacitinib programmes (table 1) and cohorts within the respective US Corrona registries (online supplementary table S7) and MarketScan database (online supplementary table S8).

Standardised IRs of VTE from the RA, PsA and PsO US Corrona registries were broadly comparable with those in the tofacitinib development programmes (online supplementary table S9). For RA patients in the MarketScan database, IRs were higher than those observed in the tofacitinib programme, but similar between those receiving tofacitinib and bDMARDs within the MarketScan database cohorts (online supplementary table S10).
Baseline demographics and disease characteristics for the subgroup analysis of the Corrona RA registry data of patients with moderate to severe disease activity $($ CDAI $>10)$ and who were aged $\geq 50$ years with $\geq 1$ cardiovascular risk factor are given in online supplementary table S11. Unadjusted IRs for DVT, PE and VTE (DVT or PE) for bDMARD-initiating (tofacitinibnaïve) patients were higher in those with cardiovascular risk factors than in the overall subgroup population (figure 6); the frequency of VTE events in patients initiating tofacitinib with cardiovascular risk factors versus the overall subgroup population was too low to draw firm conclusions (figure 6).

Among RA patients in the US Corrona registry with moderate to severe disease activity (CDAI $>10$ ) who experienced a VTE (figure 5), the median (interquartile range (IQR)) time to first 


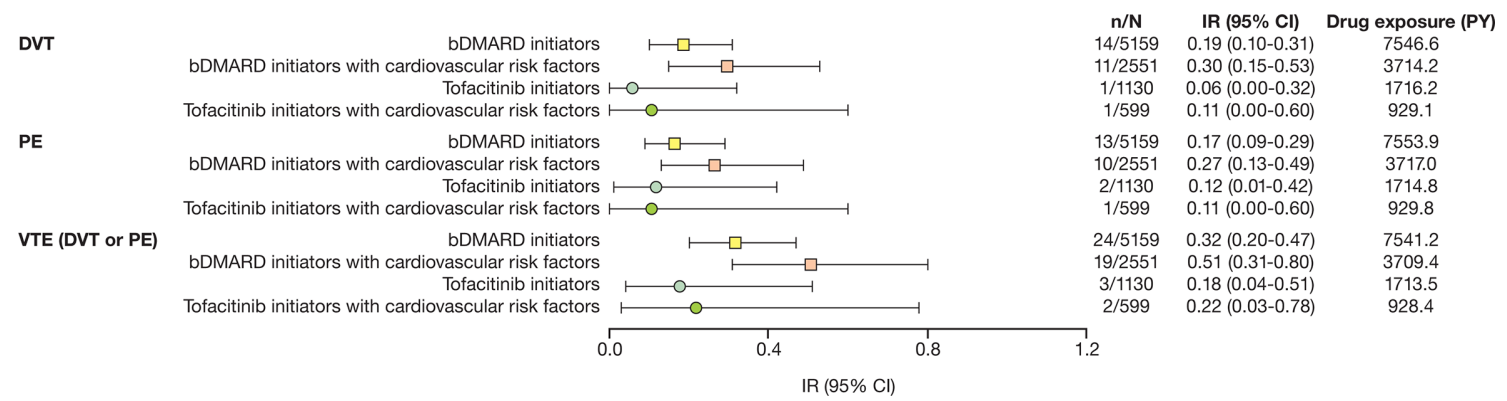

Figure 6 Drug exposure and unadjusted incidence rates $(95 \% \mathrm{Cl})$ for DVT, PE and VTE (DVT or PE) for RA patients with moderate to severe disease activity $(C D A I>10)$ in the US Corrona RA registry subanalysis who were bDMARD ${ }^{a}$ or tofacitinib ${ }^{b}$ initiators; all patients, stratified by cardiovascular risk factors. ${ }^{\mathrm{C}}{ }^{\text {a }}$ Included patients with moderate to severe RA (CDAI $>10$ at time of initiation) in the Corrona RA registry initiating a first or subsequent bDMARD (each initiation was considered separately, such that there were multiple initiations per patient) and who were tofacitinib-naïve.

${ }^{\mathrm{b}} \mathrm{RA}$ patients in the US Corrona registry initiating tofacitinib for the first time. 'Defined as patients aged $\geq 50$ years and with $\geq 1$ of the following cardiovascular risk factors: current smoker, diagnosis of hypertension, diagnosis of diabetes mellitus, history of coronary artery disease (eg, cardiac arrest, heart attack, unstable angina, revascularisation procedures), family history of premature coronary heart disease or current extra-articular RA disease. bDMARD, biologic disease-modifying antirheumatic drug; CDAI, Clinical Disease Activity Index; DVT, deep vein thrombosis; IR, incidence rate (number of patients with an event per 100 PY of exposure); N, number of RA patients; n, number of RA patients with events; PE, pulmonary embolism; PY, patient-years; RA, rheumatoid arthritis; VTE, venous thromboembolism.

event in patients initiating bDMARDs was 213.1 (91.3-334.8) days for DVT, and 395.7 (213.1-760.9) days for PE. Out of a total of 14 DVT events in patients initiating bDMARDs, four and seven events were reported within 3 and 6 months of bDMARD initiation, respectively; out of 13 PE events, none and three events were reported within 3 and 6 months of bDMARD initiation, respectively.

In patients in the Corrona RA registry with moderate to severe disease activity who were initiating tofacitinib, the time to the only reported DVT event was 608.8 days; and median (IQR) time to PE was 608.8 (91.3-1126.2) days. The DVT event did not occur within 6 months of tofacitinib initiation, and one each of the two reported PE events occurred within 3 and 6 months of initiation.

\section{Postmarketing FAERS data}

Based on 1210 unique reports (306 for embolic and thrombotic venous events, 422 for arterial events and 563 for unspecified/ mixed vessel events) with tofacitinib FAERS data, this analysis did not identify any SDRs for tofacitinib events of interest at any time point (online supplementary table S12). Most $\mathrm{O} / \mathrm{E}$ ratios for tofacitinib were $<1$; many events had an upper bound of $<1$ of the $90 \%$ interval of the $\mathrm{O} / \mathrm{E}\left(56 \%\right.$ of $\mathrm{EB}_{95} \mathrm{~s}$ and $40 \%$ of $\mathrm{ROR}_{95} \mathrm{~s}$ for PTs). Although $\mathrm{O} / \mathrm{E}$ ratios for some events were $>1$, all were still below the SDR-defined threshold of 2 or were non-significant.

\section{DISCUSSION}

The objective of this analysis was to inform about thromboembolic events across large populations of RA, PsO and PsA patients treated with tofacitinib, including analyses of patients stratified by the presence or absence of baseline cardiovascular or VTE risk factors. Analysis of the RA (excluding the ongoing Study A3921133), PsO, and PsA tofacitinib development programmes revealed similar IRs of DVT, PE, VTE (DVT or PE) and ATE events for tofacitinib, placebo, adalimumab (an active control or comparator) and methotrexate in studies of $\leq 24$ months' duration. There did not appear to be an elevated risk of thromboembolic events in the first 3 months of tofacitinib treatment, shown by the relative comparability of IR in the placebo-controlled cohorts with the other cohorts in the tofacitinib development programmes. This was reflected in data from the US Corrona RA registry, where the median time to
DVT or PE was $>200$ days for bDMARDs and $>600$ days for tofacitinib. Furthermore, IRs were consistent across tofacitinib 5 and $10 \mathrm{mg}$ twice-daily dose groups in the RA, PsO and PsA development programmes. The IRs of DVT and PE for RA, PsO and PsA were also similar to those reported in the tofacitinib UC programme, ${ }^{42}$ indicating comparable incidences of thromboembolic events with tofacitinib across diseases.

Across the tofacitinib development programmes, the IRs of DVT or PE in tofacitinib-treated patients from the all tofacitinib cohort (ranges $0.00-0.17$ and $0.00-0.15$, respectively)-including data from LTE studies with longer cumulative tofacitinib exposure-were consistent with those previously reported for patients with RA (ranges $0.21-0.62$ and $0.15-0.26$, respectively) ${ }^{19} 2022$ and PsA (0.33-0.38 and 0.11-0.12, respectively), ${ }^{22}$ who were untreated or receiving DMARDs, and for patients with severe PsO (0.36 and 0.11 , respectively). ${ }^{22}$ The IRs of ATE in the all tofacitinib cohort (range 0.22-0.52) were also similar to the IRs of ischaemic stroke $(0.3(95 \% \text { CI } 0.27-0.34))^{37}$ and myocardial infarction $(0.46$ (95\% CI $0.41-0.52))^{48}$ reported in RA patients.

As expected, subanalyses of the RA, PsO and PsA clinical programmes, stratified by the presence or absence of baseline cardiovascular risk factors, showed that patients with risk factors were more likely to experience thromboembolic events than those without. IRs in patients without risk factors were very low. Most patients who experienced thromboembolic events also had multiple cardiovascular risk factors at baseline.

The IRs of DVT and PE among patients with a baseline cardiovascular risk factor in the RA programme were higher than those without baseline cardiovascular risk factors, and are broadly comparable to those from the ad hoc safety analysis data for Study A3921133 (NCT02092467; data cut-off February 2019; database not locked; data have not yet been source-verified or subjected to standard quality-check procedures that would occur at the time of database lock, and may therefore be subject to change) (figure 7). ${ }^{1}$ The incidence of PE for tofacitinib $10 \mathrm{mg}$ twice daily was higher in the ad hoc safety analysis of Study A3921133 $(0.54(0.32-0.87))^{1}$ than that reported in the overall tofacitinib RA programme for patients with a baseline cardiovascular risk factor $(0.24(0.13-0.41))$. In addition, IRs in RA patients with cardiovascular risk factors in the US Corrona RA registry initiating tofacitinib were not higher than in those initiating bDMARDs, and were comparable to those in the RA 


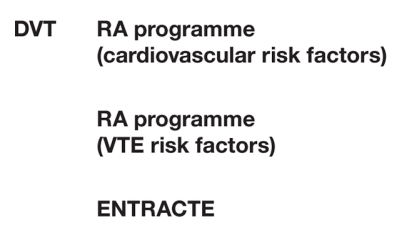

A3921133

$\begin{array}{ll}\text { PE } & \begin{array}{l}\text { RA programme } \\ \text { (cardiovascular risk factors) }\end{array}\end{array}$

RA programme
(VTE risk factors)

ENTRACTE

A3921133

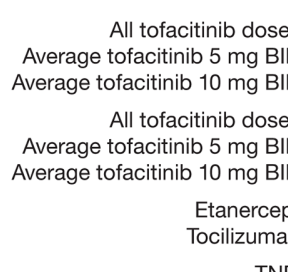

Tofacitinib 5 mg BID

Tofacitinib $10 \mathrm{mg}$ BID

All tofacitinib doses Average tofacitinib $5 \mathrm{mg}$ BID Average tofacitinib $10 \mathrm{mg}$ BID

All tofacitinib doses Average tofacitinib $5 \mathrm{mg}$ BID Average tofacitinib $10 \mathrm{mg}$ BID

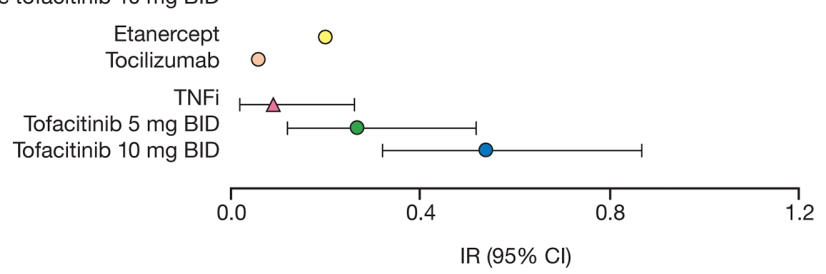

IR (95\% CI)

$0.24(0.15-0.36)$

$0.34(0.18-0.59)$

$0.17(0.08-0.32)$

$0.21(0.14-0.29)$

$0.25(0.14-0.43)^{\circ}$

$0.18(0.10-0.29)$

0.3 (NR)

0.2 (NR)

$0.18(0.07-0.39)$

$0.30(0.14-0.55)$

$0.38(0.20-0.67)$

$0.25(0.15-0.37)^{c}$

$0.25(0.12-0.48)$

$0.24(0.13-0.41)^{\circ}$

$0.18(0.12-0.26)^{\circ}$

$0.20(0.10-0.36)$

$0.17(0.10-0.27)^{\circ}$

0.2 (NR)

0.06 (NR)

$0.09(0.02-0.26)$

$0.27(0.12-0.52)$

$0.54(0.32-0.87)$

Figure 7 Incidence rates $(95 \% \mathrm{Cl})$ for DVT and PE among patients in the RA development programme, stratified by cardiovascular or VTE risk factors (all tofacitinib cohort), ${ }^{a}$ the ENTRACTE trial ${ }^{43}$ and Study A3921133. ${ }^{\text {b1 a }}$ Final data as of 18 January 2019. ${ }^{b}$ Data cut-off February 2019; database not locked. Data have not yet been source-verified or subjected to standard quality-check procedures that would occur at the time of database lock, and may therefore be subject to change. 'One patient was not counted in the numerators of the IR calculations because the event occurred outside the defined risk period. BID, twice daily; DVT, deep vein thrombosis; IR, incidence rate (number of patients with an event per 100 PY of exposure); NR, not reported; PE, pulmonary embolism; PY, patient-years; RA, rheumatoid arthritis; TNFi, tumour necrosis factor inhibitor.

tofacitinib programme, although the frequency of events was low.

Study A3921133 is designed to assess differences between tofacitinib doses, maintain patients on the same dose throughout treatment (note patients randomised to tofacitinib $10 \mathrm{mg}$ twice daily had their dose reduced to $5 \mathrm{mg}$ twice daily as per protocol amendment in February 2019), ${ }^{41}$ and encourage patients to remain in the study after treatment discontinuation. Given the observed incidence of MACE among RA patients using advanced therapies, ${ }^{49-52}$ an endpoint-driven study such as Study A3921133 was projected to take $>10$ years if enrolling a nonenriched RA population. Therefore, the study was designed to enrich for cardiovascular risk, and enrolled patients aged $\geq 50$ years and with $\geq 1$ cardiovascular risk factor, with the goal of study completion in $<8$ years.

While the results of the tofacitinib development programme did not confirm an increased VTE/ATE risk or a dose relationship, it should be noted that although the phase 2 and 3 studies did examine tofacitinib dose differences, they were limited by patient number and observation time. In the LTE studies, patients could switch dose, and did not remain in the study after treatment discontinuation. The primary objective of the LTE studies was to examine long-term safety; they were not designed to formally assess dose differences. Furthermore, not all of the cardiovascular risk factors in the A3921133 eligibility criteria could be applied to the all tofacitinib cohorts, as some information was not collected as per study protocols. None of the studies (including Study A3921133) were specifically designed to assess VTE or ATE risk. A number of potential mechanisms have been investigated to understand the increased rate of PE in Study A3921133, but the exact mechanism remains unclear. Further analyses have been initiated, including biomarker analyses of Study A3921133. ${ }^{41}$

A recently published randomised, open-label trial (ENTRACTE) evaluated the risk of MACE with the interleukin-6 inhibitor tocilizumab versus the TNFi etanercept in RA patients with an inadequate response to csDMARDs or TNFi therapy, and $\geq 1$ cardiovascular risk factor. ${ }^{43}$ Similar to Study A3921133, ENTRACTE's primary endpoints included MACE. The reported IR point estimates for DVT and PE with etanercept are consistent with those reported in the US Corrona RA registry among patients initiating bDMARDs aged $\geq 50$ years and with $\geq 1$ cardiovascular risk factor $(0.30$ and 0.27 for DVT and PE, respectively), and are higher than those observed with TNFi-treated patients in the ad hoc safety analysis data for Study A3921133 (figure 7). ${ }^{1}$

$\mathrm{RA}, \mathrm{PsO}$ and PsA patients with a baseline VTE risk factor were also more likely to experience thromboembolic events than those without. Further analysis of the patients who experienced PE in Study A3921133 is required to understand why IRs of PE were higher with tofacitinib $10 \mathrm{mg}$ twice daily versus TNFi, and if drug class affects VTE risk in patients with pre-existing risk factors. Additional analyses of the different criteria used to define cardiovascular and VTE risk factors could further refine those particular risk factors associated with thromboembolic events.

IRs of DVT, PE or ATE events from the tofacitinib development programmes were similar to age- and sex-standardised IRs from the US Corrona registries. IRs of DVT or PE events were also comparable to those previously reported for RA patients from the US Corrona registry (including tofacitinibtreated patients) in a postapproval safety study. ${ }^{45}$ The IRs from the MarketScan cohort were consistent with previously reported values, ${ }^{53}$ and no differences were observed between the tofacitinib and bDMARD cohorts. The events included in the search terms for ATE in the tofacitinib development programme comprised a broad list of PTs for SMQs (including myocardial infarction and stroke), whereas myocardial infarction and stroke events were reported separately for the MarketScan database. Although direct comparisons are limited between the tofacitinib 
development programme and the MarketScan database, the IRs of myocardial infarction and stroke in the MarketScan database suggest that overall rates of ATE were comparable between the two populations.

As patients with serious concomitant conditions are often excluded from randomised controlled trials (RCTs), real-world evidence would be expected to have higher rates of events of interest. Although data from the US Corrona registries and MarketScan database are not directly comparable with data from RCTs, these observational data were from patients selected on criteria reflecting participants in the tofacitinib development programmes; as such, we consider these appropriate for clinical context.

A published analysis of spontaneous reports in the FAERS database revealed disproportionate reporting frequencies for DVT and PE events with tofacitinib and ruxolitinib, concluding that JAK inhibitors might carry an increased risk of pulmonary thromboembolism. ${ }^{54}$ Our analysis of FAERS data did not support a signal of increased risk of VTE or ATE with tofacitinib, that is, there were no SDRs for events of interest, although differences exist between study designs, including our choice of a commonly cited SDR-defining threshold of $\mathrm{EB}_{05}>2^{47}$ that was higher than that used in the published analysis. The disproportionality analysis used here provides $\mathrm{O} / \mathrm{E}$ reporting for hypothesis generation or refinement, not for estimating IRs.

This posthoc analysis was limited by using non-adjudicated data from RA, PsO and PsA tofacitinib development programmes (plus the included RCTs not specifically designed to assess VTE or ATE risk), which limits comparisons between the tofacitinib development programmes and observational data (also not typically adjudicated), as well as precluding analyses on event severity, and event-related hospitalisations and deaths. Additionally, determining causality for hospitalisation and deaths following thromboembolic events is challenging, with unknown additional factors potentially playing a role. While the all tofacitinib cohort was not designed to examine differences between tofacitinib dose, as patients could switch tofacitinib dose in the LTE studies, most patients who entered the RA LTE study (part of the all tofacitinib cohort in the present analysis) received tofacitinib $10 \mathrm{mg}$ twice daily, and the IRs of PE were similar to those in the tofacitinib $5 \mathrm{mg}$ twice daily group, when using either the average- or constant-dose algorithm. ${ }^{55}$ An important limitation of the average tofacitinib dosing method is that a patient is assigned to the same category throughout their experience in the programme, and thus events may be attributed to a dose category different from the actual dose received at the time of the event. This approach narrows the differences between point estimates for both doses, and confounds the ability to evaluate differences between them. While the constant-dosing method addresses some limitations of average dosing, exposure and events captured after a dose switch are censored from the analysis. This results in a shorter overall tofacitinib exposure, and the risk of confounding by the reasons for discontinuation or dose change. There is also a potential for under-reporting of VTE events, particularly DVTs; a DVT is identified in $\leq 50 \%$ of PE cases, but DVT could go undetected depending on the type of diagnostic testing, or if a DVT embolises before testing. ${ }^{56-58}$ Moreover, timely access to diagnostic testing may vary by region or country, and may contribute to under-reporting of events. Data from the US Corrona registries provide real-world observational data from a wide variety of geographical sites in the USA; however, as in any observational registry, there is a possibility of channelling bias that is unmeasured with potential underascertainment. Under-reporting of VTE in the tofacitinib development programmes and observational data sources is thus problematic, which could be affected by the identification of VTE as a risk with tofacitinib treatment.

In conclusion, this analysis revealed that the incidence of DVT, PE and ATE in the tofacitinib development programmes (tofacitinib exposure of $\leq 23497 \mathrm{PY}$ in RA, $\leq 8955 \mathrm{PY}$ in $\mathrm{PsO}$ and $\leq 2038$ PY in PsA) was consistent with observational data in the US Corrona registries and MarketScan databases that include RA, PsO and PsA patients treated with non-biologic and biologic treatments. IRs of VTE and ATE in the RA, PsO and PsA tofacitinib development programmes were generally higher in patients with cardiovascular or VTE risk factors than in patients without. IRs of PE and DVT observed in patients with a baseline cardiovascular risk factor in the RA programme were similar to the Study A3921133 safety analysis, but with no evidence of differences across tofacitinib doses, which may reflect differences in study design. Future research on DVT, PE and ATE in the tofacitinib development programmes will focus on determining whether there are potential mechanistic explanations for thromboembolism related to tofacitinib use and JAK inhibition. Updates to local labelling of JAK inhibitors, such as tofacitinib, identify VTE as an important risk, and the results of this analysis highlight the importance of tailoring individual treatment while considering the risk factors for thromboembolism.

\section{Author affiliations}

${ }^{1}$ Rheumatology Clinical Research Division, Swedish Medical Center/Providence St. Joseph Health and University of Washington, Seattle, Washington, USA

${ }^{2}$ Division of Rheumatology, University of California, Los Angeles, California, USA

${ }^{3}$ Metroplex Research Center, Dallas, Texas, USA

${ }^{4}$ Inflammation and Immunology - Global Medical Affairs, Pfizer Inc, Kirkland,

Quebec, Canada

${ }^{5}$ Inflammation and Immunology, Pfizer Inc, Collegeville, Pennsylvania, USA

${ }^{6}$ Department of Epidemiology, University of Alabama at Birmingham, Birmingham, Alabama, USA

${ }^{7}$ Albany Medical College and The Center for Rheumatology, Albany, New York, USA

${ }^{8}$ Corrona LLC, Waltham, Massachusetts, USA

${ }^{9}$ Inflammation and Immunology TA, Pfizer Inc, Groton, Connecticut, USA

${ }^{10}$ Statistics, Global Product Development, Pfizer Inc, Groton, Connecticut, USA

${ }^{11}$ Clinical Development \& Operations, Pfizer Inc, Groton, Connecticut, USA

${ }^{12}$ Global Product Development, Inflammation and Immunology, Pfizer Inc, New York, New York, USA

${ }^{13}$ Worldwide Safety, Pfizer Inc, New York, New York, USA

${ }^{14}$ Department of Medicine, NYU Langone Health, New York, New York, USA

${ }^{15}$ Global Medical Epidemiology, Pfizer Inc, New York, New York, USA

${ }^{16}$ Worldwide Medical and Safety, Pfizer Inc, Collegeville, Pennsylvania, USA

${ }^{17}$ Division of Clinical Immunology and Rheumatology, University of Alabama at Birmingham, Birmingham, Alabama, USA

Acknowledgements The authors would like to thank the patients, investigators and study teams involved in the tofacitinib development programmes, US Corrona registries and IBM MarketScan research databases. Medical writing support, under the guidance of the authors, was provided by Kate Silverthorne, PhD, and Jennifer Higginson, PhD, CMC Connect, McCann Health Medical Communications and was funded by Pfizer Inc, New York, NY, USA in accordance with Good Publication Practice (GPP3) guidelines (Ann Intern Med 2015;163:461-4).

Contributors All authors provided critical revision of the manuscript. All authors interpreted the results, approved the final draft and had the final decision to submit the manuscript for publication. Pfizer Inc did not control the analysis or interpretation of the study results. Publication of this article was not contingent upon approval by Pfizer Inc.

Funding The studies included in this analysis were sponsored by Pfizer Inc, except the US Corrona registry, which was sponsored by Corrona LLC, and the analysis was funded by Pfizer Inc (access to Corrona study data was limited to Corrona, and Corrona statisticians completed all of the analyses).

Competing interests PM has received research grants and consulting fees from AbbVie, Amgen, Bristol-Myers Squibb, Celgene, Eli Lilly, Galapagos, Gilead, GlaxoSmithKline, Janssen, Novartis, Pfizer Inc, Sun and UCB; and has participated in speakers' bureaus for AbbVie, Amgen, Bristol-Myers Squibb, Celgene, Genentech, Janssen, Novartis, Pfizer Inc and UCB. CC-S has received research grants from AbbVie, Bristol-Myers Squibb and Pfizer Inc; and consulting fees from AbbVie, 
Amgen, Gilead, Pfizer Inc and Regeneron-Sanofi. SC has received consulting fees and other remuneration from AbbVie, Amgen, Boehringer Ingelheim, Gilead, Merck and Pfizer Inc. HY has received research grants from Bristol-Myers Squibb and Pfizer Inc. JK is an employee and shareholder of Corrona LLC; and has received research grants and/or consulting fees from AbbVie, Amgen, Bristol-Myers Squibb, Eli Lilly, Genentech, Novartis, Pfizer Inc, Regeneron and Sanofi. JG is an employee and shareholder of Corrona LLC. WM and AO are employees of Corrona LLC; Corrona has been supported through contracted subscriptions in the last 2 years by AbbVie, Amgen, Boehringer Ingelheim, Bristol-Myers Squibb, Celgene, Eli Lilly, Genentech, Gilead, Janssen, Merck, Novartis, Ortho Dermatologics, Pfizer Inc, Regeneron and Sun. JRC has received research grants and/or consulting fees from AbbVie, Amgen, Bristol-Myers Squibb, Corrona LLC, Crescendo Bio, Eli Lilly, Janssen, Myriad, Pfizer Inc, Roche and UCB. MH is an employee of Pfizer Inc and owns stock/stock options in Pfizer Inc and in other pharmaceutical companies that may manufacture and/or market drugs mentioned in this article or from the same pharmacological/therapeutic class. LF, JW, KSK, DG, CW, CC, HV, EH, AM and TVJ are employees and shareholders of Pfizer Inc.

Patient and public involvement Patients and/or the public were not involved in the design, or conduct, or reporting or dissemination plans of this research.

Patient consent for publication All patients provided informed consent.

Ethics approval Institutional review board approval was provided by all participating institutions.

Provenance and peer review Not commissioned; externally peer reviewed.

Data availability statement Upon request, and subject to certain criteria, conditions and exceptions (see https://www.pfizer.com/science/clinical-trials/ trial-data-and-results for more information), Pfizer will provide access to individual deidentified participant data from Pfizer-sponsored global interventional clinical studies conducted for medicines, vaccines and medical devices (1) for indications that have been approved in the USA and/or EU, or (2) in programmes that have been terminated (ie, development for all indications has been discontinued). Pfizer will also consider requests for the protocol, data dictionary and statistical analysis plan. Data may be requested from Pfizer trials 24 months after study completion. The deidentified participant data will be made available to researchers whose proposals meet the research criteria and other conditions, and for which an exception does not apply, via a secure portal. To gain access, data requestors must enter into a data access agreement with Pfizer.

Open access This is an open access article distributed in accordance with the Creative Commons Attribution Non Commercial (CC BY-NC 4.0) license, which permits others to distribute, remix, adapt, build upon this work non-commercially, and license their derivative works on different terms, provided the original work is properly cited, appropriate credit is given, any changes made indicated, and the use is non-commercial. See: http://creativecommons.org/licenses/by-nc/4.0/.

\section{ORCID iDs}

Philip Mease http://orcid.org/0000-0002-6620-0457

Jeffrey R Curtis http://orcid.org/0000-0002-8907-8976

\section{REFERENCES}

1 European Medicines Agency. Xeljanz (tofacitinib) - summary of product characteristics, 2020. Available: https://www.ema.europa.eu/en/documents/product-information/ xeljanz-epar-product-information_en.pdf [Accessed 12 Jun 2020].

2 US Food and Drug Administration. XELJANZ® (tofacitinib): highlights of prescribing information, 2019. Available: https://labeling.pfizer.com/ShowLabeling.aspx?id=959 [Accessed 11 Nov 2019].

3 US Food and Drug Administration. OLUMIANT (baricitinib): highlights of prescribing information, 2018. Available: https://www.accessdata.fda.gov/drugsatfda_docs/label/ 2018/207924s000lbl.pdf [Accessed 5 Jun 2019].

4 European Medicines Agency. Olumiant (baricitinib) - summary of product characteristics, 2017. Available: http://www.ema.europa.eu/docs/en_GB/document library/EPAR_-_Product_Information/human/004085/WC500223723.pdf [Accessed 5 Jun 2019].

5 US Food and Drug Administration. RINVOQTM (upadacitinib): highlights of prescribing information, 2019. Available: https://www.accessdata.fda.gov/drugsatfda_docs/label/ 2019/211675s000lbl.pdf [Accessed 31 Oct 2019].

6 European Medicines Agency. RINVOQ (upadacitinib) - summary of product characteristics, 2019. Available: https://www.ema.europa.eu/en/documents/ product-information/rinvoq-epar-product-information_en.pdf [Accessed 28 Jan 2020].

7 Nowak M, Królak-Nowak K, Sobolewska-Włodarczyk A, et al. Elevated risk of venous thromboembolic events in patients with inflammatory myopathies. Vasc Health Risk Manag 2016;12:233-8.

8 Tanaka T, Ozaki K. Inflammation as a risk factor for myocardial infarction. J Hum Genet 2006:51:595-604.

9 Aksu K, Donmez A, Keser G. Inflammation-induced thrombosis: mechanisms, disease associations and management. Curr Pharm Des 2012;18:1478-93.
10 van den Oever IAM, Sattar N, Nurmohamed MT. Thromboembolic and cardiovascular risk in rheumatoid arthritis: role of the haemostatic system. Ann Rheum Dis 2014;73:954-7.

11 Falanga A, Russo L, Milesi V, et al. Mechanisms and risk factors of thrombosis in cancer. Crit Rev Oncol Hematol 2017;118:79-83.

12 Sweetland S, Parkin L, Balkwill A, et al. Smoking, surgery, and venous thromboembolism risk in women: United Kingdom cohort study. Circulation 2013;127:1276-82.

13 Gaertner S, Cordeanu E-M, Mirea C, et al. Increased risk and severity of unprovoked venous thromboembolism with clustering cardiovascular risk factors for atherosclerosis: results of the REMOTEV registry. Int I Cardiol 2018;252:169-74.

14 Rott H. Prevention and treatment of venous thromboembolism during HRT: current perspectives. Int I Gen Med 2014;7:433-40.

15 Zakai NA, McClure LA, Judd SE, et al. Racial and regional differences in venous thromboembolism in the United States in 3 cohorts. Circulation 2014;129:1502-9.

16 Ageno W, Becattini C, Brighton T, et al. Cardiovascular risk factors and venous thromboembolism: a meta-analysis. Circulation 2008;117:93-102.

17 Heit JA, Spencer FA, White RH. The epidemiology of venous thromboembolism. J Thromb Thrombolysis 2016;41:3-14.

18 Chung W-S, Peng C-L, Lin C-L, et al. Rheumatoid arthritis increases the risk of deep vein thrombosis and pulmonary thromboembolism: a nationwide cohort study. Ann Rheum Dis 2014;73:1774-80.

19 Choi HK, Rho Y-H, Zhu Y, et al. The risk of pulmonary embolism and deep vein thrombosis in rheumatoid arthritis: a UK population-based outpatient cohort study. Ann Rheum Dis 2013;72:1182-7.

20 Kim SC, Schneeweiss S, Liu J, et al. Risk of venous thromboembolism in patients with rheumatoid arthritis. Arthritis Care Res 2013;65:1600-7.

21 Lee JJ, Pope JE. A meta-analysis of the risk of venous thromboembolism in inflammatory rheumatic diseases. Arthritis Res Ther 2014;16:435.

22 Ogdie A, Kay McGill N, Shin DB, et al. Risk of venous thromboembolism in patients with psoriatic arthritis, psoriasis and rheumatoid arthritis: a general population-based cohort study. Eur Heart J 2018;39:3608-14.

23 Matta F, Singala R, Yaekoub AY, et al. Risk of venous thromboembolism with rheumatoid arthritis. Thromb Haemost 2009:101:134-8.

24 Ramagopalan SV, Wotton CJ, Handel AE, et al. Risk of venous thromboembolism in people admitted to hospital with selected immune-mediated diseases: record-linkage study. BMC Med 2011;9:1

25 Zöller B, Li X, Sundquist J, et al. Risk of pulmonary embolism in patients with autoimmune disorders: a nationwide follow-up study from Sweden. Lancet 2012:379:244-9.

26 Kang J-H, Keller JJ, Lin Y-K, et al. A population-based case-control study on the association between rheumatoid arthritis and deep vein thrombosis. J Vasc Surg 2012;56:1642-8.

27 Bacani AK, Gabriel SE, Crowson CS, et al. Noncardiac vascular disease in rheumatoid arthritis: increase in venous thromboembolic events? Arthritis Rheum 2012;64:53-61.

28 Holmqvist ME, Neovius M, Eriksson J, et al. Risk of venous thromboembolism in patients with rheumatoid arthritis and association with disease duration and hospitalization. JAMA 2012;308:1350-6.

29 Yusuf HR, Hooper WC, Grosse SD, et al. Risk of venous thromboembolism occurrence among adults with selected autoimmune diseases: a study among a U.S. cohort of commercial insurance enrollees. Thromb Res 2015;135:50-7.

30 Liang KP, Liang KV, Matteson EL, et al. Incidence of noncardiac vascular disease in rheumatoid arthritis and relationship to extraarticular disease manifestations. Arthritis Rheum 2006;54:642-8.

31 Rhee T-M, Lee JH, Choi E-K, et al. Increased risk of atrial fibrillation and thromboembolism in patients with severe psoriasis: a nationwide population-based study. Sci Rep 2017;7:9973.

32 Ahlehoff $\mathrm{O}$, Gislason $\mathrm{GH}$, Lindhardsen J, et al. Psoriasis carries an increased risk of venous thromboembolism: a Danish nationwide cohort study. PLoS One 2011;6:e18125.

33 Lutsey PL, Prizment AE, Folsom AR. Psoriasis is associated with a greater risk of incident venous thromboembolism: the lowa Women's Health Study. J Thromb Haemost 2012;10:708-11.

34 Ahlehoff $\mathrm{O}$, Gislason G, Lamberts M, et al. Risk of thromboembolism and fatal stroke in patients with psoriasis and nonvalvular atrial fibrillation: a Danish nationwide cohort study. J Intern Med 2015;277:447-55.

35 Chung W-S, Lin C-L. Increased risks of venous thromboembolism in patients with psoriasis. A nationwide cohort study. Thromb Haemost 2017;117:1637-43.

36 Horreau C, Pouplard C, Brenaut E, et al. Cardiovascular morbidity and mortality in psoriasis and psoriatic arthritis: a systematic literature review. J Eur Acad Dermatol Venereol 2013;27(Suppl 3):12-29.

37 Wiseman SJ, Ralston SH, Wardlaw JM. Cerebrovascular disease in rheumatic diseases: a systematic review and meta-analysis. Stroke 2016;47:943-50.

38 Bengtsson $\mathrm{K}$, Forsblad-d'Elia $\mathrm{H}$, Lie E, et al. Are ankylosing spondylitis, psoriatic arthritis and undifferentiated spondyloarthritis associated with an increased risk of cardiovascular events? A prospective nationwide population-based cohort study. Arthritis Res Ther 2017;19:102. 
39 Poudel D, Dhital R, Khanal R, et al. Association of venous thromboembolism with spondyloarthopathies among hospitalized patients - data from national inpatient sample [abstract]. Arthritis Rheumatol 2017;69:Abstract 879.

40 ClinicalTrials.gov. Safety study of tofacitinib versus tumor necrosis factor (TNF) inhibitor in subjects with rheumatoid arthritis, 2017. Available: https://clinicaltrials. gov/ct2/show/NCT02092467 [Accessed 29 Oct 2019].

41 European Medicines Agency. Pharmacovigilance Risk Assessment Committee (PRAC) assessment report, 2020. Available: https://www.ema.europa.eu/en/documents/ referral/xeljanz-h-20-1485-c-4214-0017-assessment-report-article-20_en.pdf [Accessed 9 Apr 2020].

42 Sandborn WJ, Panés J, Sands BE, et al. Venous thromboembolic events in the tofacitinib ulcerative colitis clinical development programme. Aliment Pharmacol Ther 2019;50:1068-76.

43 Giles JT, Sattar N, Gabriel S, et al. Cardiovascular safety of tocilizumab versus etanercept in rheumatoid arthritis: a randomized controlled trial. Arthritis Rheumatol 2020;72:31-40.

44 CORRONA. Corrona registry, 2017. Available: https://www.corrona.org/registries/ [Accessed 5 Mar 2020].

45 Kremer J, Bingham C, Cappelli L, et al. Post-approval comparative safety study of tofacitinib and biologic DMARDs: five-year results from a US-based rheumatoid arthritis registry [abstract]. Ann Rheum Dis 2019;78:Abstract OP0028.

46 IBM. Marketscan databases, 2015. Available: https://www.ibm.com/products/ marketscan-research-databases/details [Accessed 2 Mar 2019].

47 Harpaz R, DuMouchel W, LePendu P, et al. Performance of pharmacovigilance signaldetection algorithms for the FDA adverse event reporting system. Clin Pharmacol Ther 2013;93:539-46.

48 Pujades-Rodriguez M, Duyx B, Thomas SL, et al. Rheumatoid arthritis and incidence of twelve initial presentations of cardiovascular disease: a population record-linkage cohort study in England. PLoS One 2016;11:e0151245.

49 Curtis JR, Mariette X, Gaujoux-Viala C, et al. Long-term safety of certolizumab pegol in rheumatoid arthritis, axial spondyloarthritis, psoriatic arthritis, psoriasis and
Crohn's disease: a pooled analysis of 11317 patients across clinical trials. RMD Open 2019;5:e000942.

50 Taylor PC, Weinblatt ME, Burmester GR, et al. Cardiovascular safety during treatment with baricitinib in rheumatoid arthritis. Arthritis Rheumatol 2019;71:1042-55.

51 Cohen S, van Vollenhoven R, Winthrop K, et al. Safety profile of upadacitinib in rheumatoid arthritis: integrated analysis from the SELECT Phase 3 clinical program [abstract]. Arthritis Rheumatol 2019;71:Abstract 509.

52 Charles-Schoeman C, DeMasi R, Valdez H, et al. Risk factors for major adverse cardiovascular events in phase III and long-term extension studies of tofacitinib in patients with rheumatoid arthritis. Arthritis Rheumatol 2019;71:1450-9.

53 Liang H, Danwada R, Guo D, et al. Incidence of inpatient venous thromboembolism in treated patients with rheumatoid arthritis and the association with switching biologic or targeted synthetic disease-modifying antirheumatic drugs (DMARDs) in the realworld setting. RMD Open 2019;5:e001013.

54 Verden A, Dimbil M, Kyle R, et al. Analysis of spontaneous postmarket case reports submitted to the FDA regarding thromboembolic adverse events and JAK inhibitors. Drug Saf 2018;41:357-61

55 Wollenhaupt J, Lee E-B, Curtis JR, et al. Safety and efficacy of tofacitinib for up to 9.5years in the treatment of rheumatoid arthritis: final results of a global, open-label, long-term extension study. Arthritis Res Ther 2019;21:89.

56 Becattini C, Cohen AT, Agnelli G, et al. Risk stratification of patients with acute symptomatic pulmonary embolism based on presence or absence of lower extremity DVT: systematic review and meta-analysis. Chest 2016;149:192-200.

57 Sane MA, Laukkanen JA, Granér MA, et al. Pulmonary embolism location is associated with the co-existence of the deep venous thrombosis. Blood Coagul Fibrinolysis 2019:30:188-92.

58 van Langevelde K, Srámek A, Vincken PWJ, et al. Finding the origin of pulmonary emboli with a total-body magnetic resonance direct thrombus imaging technique. Haematologica 2013;98:309-15. 